\title{
Age and gender differences in the spectral characteristics of Korean sibilants*
}

\author{
Eun Jong Kong ${ }^{1, * *} \cdot$ Jieun Kang ${ }^{2}$ \\ ${ }^{I}$ Department of English, Korea Aerospace University, Goyang, Korea \\ ${ }^{2}$ Department of English Language and Literature, Korea University, Seoul, Korea
}

\begin{abstract}
While recent acoustic studies have reported associations of fronted sibilants (fricatives $/ \mathrm{s} \mathrm{s}^{*} /$ and affricates $/ \mathrm{tc}_{6} \mathrm{tc}^{*} /$ ) with gender in Seoul Korean, there have not been any studies examining the relationship of the variants with adult speakers' ages. The current study analyzes sibilant productions from 39 adult speakers born between 1942 and 2008 (19 females) in terms of spectral peak frequencies (SPFs) in frication, an acoustic index of place of articulation (POA). The results indicate some phonetic contexts where higher sibilant SPFs, i.e., fronter POAs, are associated with younger adults and those fronted variants are realized in a gender-differentiated manner -- tense affricates and word-initial tense fricatives before /i/ in the females' productions, and word-medial tense fricatives before $/ \mathrm{a} /$ in the males' productions. The findings confirm that the distributions of the fronted sibilants are accounted for not only by the speakers' gender but also by their ages, indicating that the fronted variants are innovative forms of realizing sibilants in Seoul Korean. In addition, the current results convincingly show that the fronted sibilant variants are not mere reflections of individuals' physiological differences since they are not observed across all of the examined phonetic contexts.
\end{abstract}

Keywords: fronted sibilant in Seoul Korean, frication constriction place, spectral peak frequency, age difference, gender difference

\section{Introduction}

While phonological categories of the same language are realized in physically different forms, those variations are not random but systematic, conditioned by phonetic contexts (e.g., segmental and suprasegmental environments), speakers' biological attributes (e.g., height, sex and age) or cultural and stylistic choices (e.g., gender, and class markers). To take a specific example of a non-tense sibilant fricative $/ \mathrm{s} /$ in Korean, the phonological process describes that a post-consonantal vocalic context of /i/ consistently accompanies (post-alveolar or) palatalized variants of fricatives (e.g., Shin, 2012). These palatalized variants of $/ \mathrm{s} /$ in Korean are realized as lower frequency of spectral peaks than those of alveolar fricatives, as the longer front cavity associated with a backer constriction place of

\footnotetext{
* This work was supported by the Ministry of Education of the Republic of Korea and the National Research Foundation of Korea (NRF-2017 S1A5A2A01024268).

** ekong@kau.ac.kr, Corresponding author

Received 14 February 2021; Revised 10 March 2021; Accepted 13 March 2021

(c) Copyright 2021 Korean Society of Speech Sciences. This is an Open-Access article distributed under the terms of the Creative Commons Attribution NonCommercial License (http://creativecommons.org/licenses/by-nc/4.0) which permits unrestricted non-commercial use, distribution, and reproduction in any medium, provided the original work is properly cited.
} 
articulation (POA) results in spectral energy concentration at a lower frequency range (e.g., Jongman et al., 2000; Hahm, 2007). Language-universally, the size of an individual's oral cavity contributes to acoustic variations of fricatives, where male speakers have overall lower spectral peak frequencies (SPFs) than female speakers due to their larger oral cavities (e.g., Flipsen et al., 1999; Jongman et al., 2000). For stylistic or indexical reasons, this relationship between gender-related physiological characteristics and acoustic outputs can be deliberately exploited by some community members to represent gender identity and class (e.g., Hu, 1991 [feminine accent in Mandarin Chinese]; Stuart-Smith, 2007). For one, Stuart-Smith (2007) showed that working-class female English speakers in Glasgow indicated their social class by producing fricatives with lower frequency centers of gravity in frication spectra than non-working-class females.

Among the various conditions potentially responsible for realizations of speech categories, the current study explores two speaker features, namely, age and gender, in describing acoustic variations of sibilant consonants in Seoul Korean: affricates /tc, t6*/ (下, ㅈ, lax and tense phonation types, respectively) and fricatives /s, $\mathrm{s}^{* /}$ (入, 从, non-tense (or lax) and tense types, respectively). The study has a specific goal of documenting how recently reported variants of fronted sibilants are distributed in adult speakers' productions according to their gender and age. To briefly review the POAs of sibilant fricatives in Seoul Korean, fricatives $/ \mathrm{s}, \mathrm{s} * /$ are almost unarguably known to be alveolar consonants $\left[\mathrm{s}, \mathrm{s}^{*}\right]$ with no phonological contrast of POA, but they have (post-alveolar or) palatalized allophones $\left[6,6^{*}\right]$ before a high front vowel /i/ (Lee, 1996; Shin, 2012). Affricates /tc, to*/ in Seoul Korean are similar to fricatives in that they have no phonological contrast of POA, but unlike fricatives, the affricates have no allophonic variations due to following vocalic contexts. With reference to the fricative POAs, an affricate POA can be described to be more back than alveolar fricatives $\left[\mathrm{s}, \mathrm{s}^{*}\right]$ and is as back as alveolopalatal allophones of fricatives $\left[6,6^{*}\right]$. (It should be noted that there are other arguments on affricate POAs such as palato-alveolar affricates [Kim \& Ahn, 1988] and alveolo-palatal or palatal affricates [Hume, 1990] based on phonological evidence).

To provide acoustic evidence of sibilant POAs in Korean, two previously published studies by the authors and colleagues examined the spectral properties of Korean sibilants collected from university students in their 20s and reported two types of gender-differentiated fronted variants: (1) fronted variants of female speakers' wordmedial affricates (Kong et al., 2014), and (2) fronted variants of male speakers' fricatives (before non-/i/ vowels) (Kong \& Kang, 2020). First, Kong et al. (2014) examined sibilants produced by 42 young adult speakers and found that the SPFs of the females' affricates before /a/ were no lower than those of alveolar fricatives in word-medial context. Comparable SPF values between affricates and fricatives can imply closer places of articulation, suggesting that females' affricate POAs are almost as fronted as alveolar fricatives. More recently, Kong \& Kang (2020) reported another kind of fronted sibilant based on acoustic analyses using a new database of fricative productions. The SPFs of the university students' $(\mathrm{N}=32)$ fricatives before non-/i/ vowels were not statistically different between male and female speakers. This pattern was interpreted to infer that males' fricative POAs were somewhat fronted, since otherwise lower SPFs are expected in males' fricatives than those of the females' tokens. Moreover, the study described the male speakers' fricatives as having relatively diffused spectral energy distributions, pointing out an acoustic characteristic of non-sibilant consonants in the males' fricative realizations.

Despite robust acoustic evidence of gendered fronted sibilants, the two previous studies were not able to provide a full picture of sibilant POAs in Korean, lacking a consideration of speakers of other age groups such as older adults. Based on the assumption that an individual's linguistic structures stay relatively unchanged over a lifetime (apparent-time hypothesis: Labov, 1963; Sankoff, 2006), cross-sectional research looking into multiple age groups can be useful in revealing whether the target variants represent new entries into the speech community. If the fronted sibilants turn out to be utilized only by young speakers but not by old speakers, that will support the conclusion that the variants never existed in earlier days for the old generation in Seoul Korean. This will prove the fronted sibilants are innovative forms for the young generation. Once the variants are identified as new, we can further discuss the impacts and implications that these appearances may carry on the language. Innovative forms might indicate a change, predicting that the new forms from the young generation will spread to the rest of the population in the community (e.g., Labov, 1963; Ohala, 1993; Sankoff, 2006). Alternatively, independent of phonological implications, new phonetic forms may represent socio-indexical values of speech community members such as class and gender identity or idiosyncratic characteristics (e.g., Labov, 1990; Eckert, 1989). Before digging into further discussion on the structural and social implications of the fronted sibilants in Seoul Korean, experimental evidence should be sought to explain how those variants are distributed across speakers' gender and age. In this study, we aim to examine whether the variants innovative realizations by investigating how young and old adults realize sibilant POAs. The current study is a follow-up analysis for Kong \& Kang (2020), sharing the same sibilant production database. Using the same acoustic measures (i.e., spectral peak frequency to index fricative POA), the study analyzes sibilants produced by speakers for an extended age range, including old adults in their 40s to 70 s.

\section{Methods}

\subsection{Participants, tasks and procedures}

The present study analyzed a subset of a larger production data where a total of 80 speakers between the ages of 10 and 76 produced words and sentences by participating in four tasks (i.e., the tasks of word-list reading, picture-naming, narration and paired dialogues). They were speakers of Seoul Korean. We selected 18 university students (born between 1991 and 2008) and 21 older adults (born between 1942 and 1982) out of the original 80 speakers, trying to balance gender (nine younger adult females and ten older adult females), and performed a spectral analysis of fricatives and affricates elicited in a picture-naming task.

During the picture-naming task (E-Prime 2 software (Psychology Software Tools, 2016)), simple visual images appeared on a computer screen prompting the participants to recall the target words and speak them into the microphone (Shure SM80). Their production responses were recorded through a digital recorder (Marantz digital recorder PMD661) at a 44,100 $\mathrm{Hz}$ sampling rate and 16-bit quantization. Corrections were not made even if the speakers produced erroneous words such as synonyms; those off-targets were 
discarded later in the analysis.

\subsection{Materials}

The target consonants (/s, s*/ 入, 从, /t $6, \mathrm{t}^{*} /$ 下, 不) before /i/ or /a/ vowel contexts were realized in 55 different words (28 wordinitial and 27 word-medial target words). Appendix 1 presents a list of stimulus words separated by phonetic contexts. Stimulus words were nouns (with a few exceptions of verbs) that are relatively easy to be prompted in visual image stimuli with the picture-naming task taken into a consideration.

\subsection{Acoustic analysis}

Adopting the same analysis protocol from Kong \& Kang (2020), the authors labeled the acoustic events in the target sibilants. The labelers went over each sibilant consonant and identified the frication beginnings (fric On) and endings (fricOff) by visually inspecting the spectrogram evidence of high frequency energy concentration. Sibilant consonants whose frication durations (timestamp [fricOff] minus timestamp [fric On]) exceeded $25 \mathrm{~ms}$ were included in the spectral analysis. FFF frication spectrum of 1,832 tokens in total ( 880 word-initial and 952 word-medial tokens) was created based on the $25 \mathrm{~ms}$ Hamming window centered at the frication midpoint. A high band pass filter $(1,000 \mathrm{~Hz}-11,025 \mathrm{~Hz})$ was applied with pre-emphasis above $1,000 \mathrm{~Hz}$. The peak frequency of the frication spectrum (Spectral Peak Frequency: SPF) was extracted to be used as an acoustic correlate of frication constriction location (frication POA) (Jongman et al., 2000). Figure 1 illustrates an example of acoustic event labelling and spectrum of a word-initial /si/ token. The spectral analysis was carried out in Praat (Paul \& David, 2021).

\subsection{Statistical analysis}

The mixed-effects logistic regression models were made to predict SPF variations via interactions of three fixed-effect variables: (1) speakers' birthyear (continuous variable), (2) manner of articulation (fricative vs. affricate) and (3) vocalic context (/a/ vs. /i/), using a treatment coding scheme built in $\mathrm{R}$ ( $\mathrm{R}$ Core Team, 2020). The model calculated by-subject random intercepts and slopes of vowels and manner. We constructed eight separate regression models according to prosodic positions (word-initial and word-medial tokens), speaker gender (female and male) and phonation types (lax and tense) after observing relatively discrepant patterns of interactions with a birthyear variable in pilot models (see Figure 3). The model separation was chosen to avoid overly complicated interpretations of more than three variables in a regression model structure. Statistical models were made using lmer and lmerTest (Bates et al., 2015; Kuznetsova et al., 2017) in R.
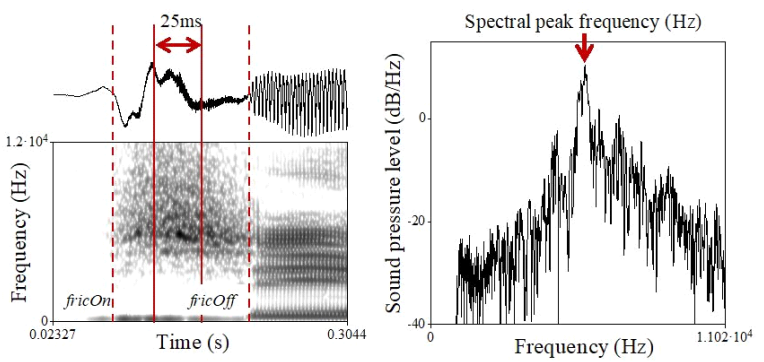

Figure 1. Illustrations of acoustic event labels (left) and peak frequency of frication spectrum (right)

\section{Results}

\subsection{SPF realizations of affricates and fricatives}

Before statistically testing the effect of age (as a continuous variable) in realizations of the Korean sibilants, we made a visual inspection of aggregated SPF values separated by two discrete speaker groups of young adults (in their 20s) and older adults (ranging from their 40s to 70s). Figure 2 displays the SPF means and standard deviations of sibilant frication before /a/ and /i/ separated by gender, phonation types and prosodic locations.

In Figure 2a, in terms of the SPF means of older adults' fricative consonants, it was observed that fricatives before $/ \mathrm{a} / \mathrm{had}$ the highest SPF means, and those before /i/ had the lowest SPF means. This pattern was shared by males and females, lax and tense types, and word initial and word medial positions. These acoustic characteristics are in line with the previously known constriction location differences of Korean sibilant fricatives between /a/ and /i/ vowel contexts, confirming that $/ \mathrm{s}, \mathrm{s}^{*} /+/ \mathrm{a} /$ is articulated at an anterior location to $/ \mathrm{s}$,

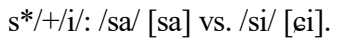

In contrast to fricatives, older speakers' affricates did not show noticeable differences in SPF means between /a/ and /i/ contexts. In fact, affricates had similar SPF means before /a/ and /i/, which were no higher than those of fricatives $+/ \mathrm{i} /$. The acoustic characteristics of the affricate SPFs from the older adults indicate that the frication constrictions of the affricates are made at a position no fronter than fricatives before $/ \mathrm{i} /$.

While young adult speakers exhibited similar patterns to older speakers with respect to fricative SPF means before /a/ and /i/ contexts - fricative SPFs before /a/ were consistently higher than those before $/ \mathrm{i}$ /, their affricate realizations differed from older adults in that they showed gender-differentiated characteristics in the SPF means (see Figure 2b). Young male speakers had affricate SPF means no higher than those of fricatives $+/ \mathrm{i} /$, as observed in the older adults' patterns. In contrast, the females' affricates did not necessarily follow the SPF patterns of the older adults' affricates, which were as low as the fricatives before /i/, but had affricate SPF means almost as high as those of the alveolar fricatives' before /a/. For example, in Figure $2 b$, the word-medial lax affricates before /a/ and /i/ had SPF means no lower than the fricative SPFs before /a/, suggesting that the lax affricate frication constrictions were made at an anterior location. In a similar fashion, word-medial tense affricates before /a/ had SPF means no lower than alveolar fricatives.

As another gender-differentiated SPF pattern, it was also noted that the female speakers' word-medial tense sibilants (both affricates and fricatives) had similar SPF means, which were as high as the fricatives before /a/. Even the fricatives before /i/ had comparably high SPF means in this prosodic location, although it was still $/ \mathrm{s}^{*} \mathrm{a} /$ that had the highest SPF means. For the young adult female speakers, the sibilants of the tense phonation-type were as fronted as the alveolar POA in the word-medial position.

To summarize, the young adult female speakers' sibilants appeared to be differentiated from young male speakers and older speakers by being realized as relatively fronted forms, although the contexts were not broad. We further tested these age- and gender- differentiated SPF patterns using statistical models in the following section. 


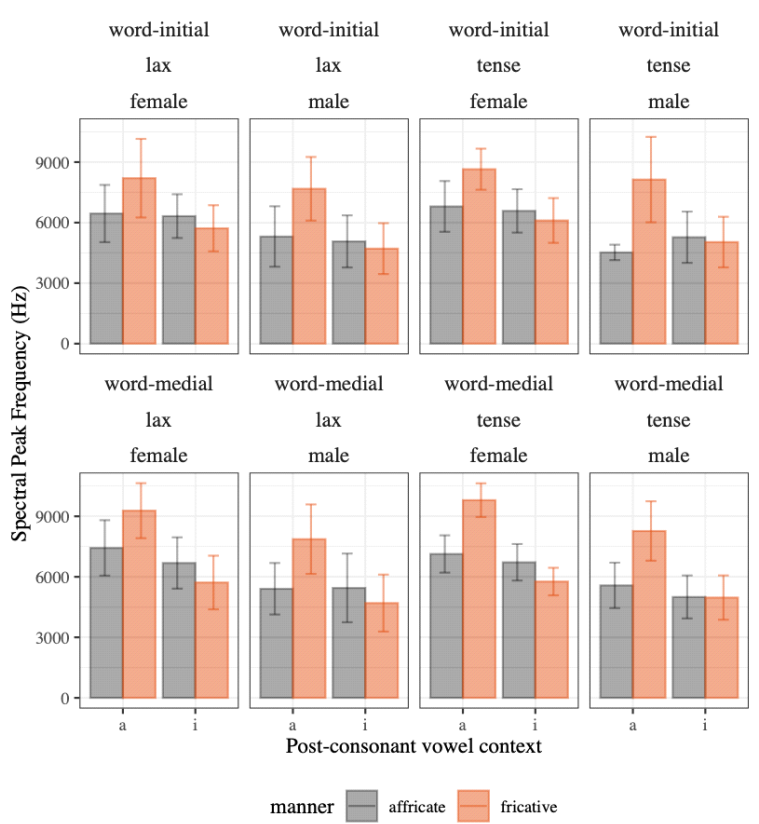

(a) Older adult speakers

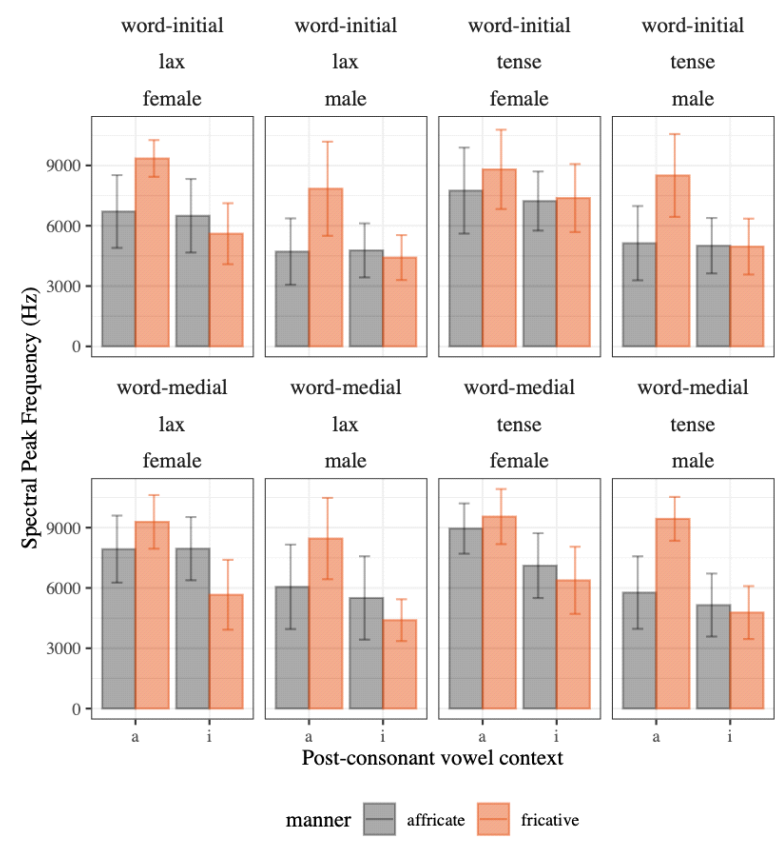

(b) Young adult speakers

Figure 2. (a) Older speakers' and (b) younger speakers' sibilants: SPF means of affricates (grey) and fricative (red) before /a/ and i/ contexts, separated by prosodic conditions (top row for word-initial tokens, and bottom panels for word-medial tokens), phonation types (two left columns for the lax type, and two right columns for the tense types), and gender. Error bars indicate \pm one standard deviations

\subsection{Age and gender differences in SPF realizations}

Figure 3 plots the sibilant SPFs (by /a/ and /i/ conditions) as a function of speakers' birthyear and Tables 1,2 present summaries of the mixed-effects regression models where the SPF variations of sibilants are predicted by age (speakers' birthyear) with an interaction of consonant manner (affricate vs. fricative) and vowel contexts (/a/ vs. /i/) (underlined represents the reference level of the contrasts).

Males' sibilant production models: Figure $3 \mathrm{a}$ displays the scatterplots of SPFs against birthyear (older to younger speakers) and their linear trend lines, showing that the overall changes for male speakers' sibilant SPFs were so small across ages that the trend lines were almost flat. In addition, it was observed that, across birthyear, the SPFs of fricatives $+/ \mathrm{a} /$ were overall higher than the SPFs of the other sibilants (fricatives $+/ \mathrm{i} /$, and affricates $+/ \mathrm{a} /$ and $/ \mathrm{i} /$ ) as described in Section 3.1.

As summarized in Table 1, the regression models confirmed that the effect of age was not significant in explaining the SPF variations of affricates $+/ \mathrm{i} /$ (see Birthyear rows in each model), and affricates + /a/ (when tested in another set of models by switching the reference level to /a/, beta coefficients of Birthyear were $p>.05$ ), as shown in the nearly flat linear trend lines of the males' affricates. Unlike the affricates $+/ \mathrm{a}, \mathrm{i} / \mathrm{and}$ fricatives of most conditions, the effect of age was significant in explaining the SPFs of the word-medial tense fricatives $+/ \mathrm{a} /(/ \mathrm{s} * \mathrm{a} /$ 싸); the SPFs produced an increasing trend line as a function of birthyear $\left(\beta_{\text {Birthyear }}=27\right.$, S.E. $=8.4, p<.005$, estimated in the model where fricative $+/ \mathrm{a} /$ was set as the reference level). This means that the young male speakers' $/ \mathrm{s} * \mathrm{a} /$ productions had relatively higher SPFs than those of older speakers, characterizing young adults' word-medial fricatives as fronted articulations distinguished from those of older speakers (Kong \& Kang, 2020).

In terms of the overall SPF differences between consonants, the models estimated that the SPFs of the affricates $+/ \mathrm{i} /$ were not significantly higher than those of the fricatives $+/ \mathrm{i} /$; the Manner rows of each model provided no significant SPF differences between affricate and fricative given the vocalic condition (e.g., WI-lax: $\beta$ fric-aff $=-414$, S.E. $=407, p=.31$ ). Given the manner (=affricate), the estimated SPFs of the affricates before /i/ were not significantly different from those before /a/; see the Vowel rows of each model (e.g., WI-lax: $\beta_{/ \mathrm{a}-/ \mathrm{i}}=-202$, S.E. $=428, p=.64$ ). In contrast, the models showed statistically meaningful differences between the estimated SPFs of the affricates $+/ \mathrm{i} /$ and those of the fricatives $+/ \mathrm{a} /$; see the Manner $\times$ Vowel rows of each model (e.g., WI-lax: $\beta_{\text {fricative }+/ a-/ \text { affricate }+/ i=}=$ $3,395$, S.E. $=475, p<.0005)$. These model summaries confirmed that the male speakers' affricates had their frication constrictions as back as those of the fricatives $+/ \mathrm{i} /$ and significantly more back than those of the fricatives $+/ \mathrm{a} /$. It is noted that while these SPF differences were estimated by positing the youngest adults' birthyear as the reference year (year 2008=0), the patterns of the SPF differences between manners, vowels, and their interactions were identical in another set of models with the oldest speakers' birthyear (year 1942) set as 0 , as the lack of age effect suggested.

Females' sibilant production models: Figure 3 b shows that, while the trend lines for the SPFs of the fricatives $+/ \mathrm{a} /$ were relatively flat in all conditions, those of the fricatives $+/ \mathrm{i} /$ and affricates $+/ \mathrm{a}, \mathrm{i} /$ tended to increase across birthyear in some contexts. The regression models for the females' sibilants turned out to reveal a significant age effect in explaining variations of affricate SPFs. As presented in Table 2, in the /i/ context, the SPFs of the word-initial tense affricates $(/ \mathrm{t} 6 * \mathrm{i} /$ 찌 $)$ and those of the word-medial lax affricates (/tci/ 지) increased as the speakers' birthyears increased (WI-찌: $\beta_{\text {Birthyear }}=$ 24 , S.E. $=10, p<.05$; WM-지: $\beta_{\text {Birthyear }}=39$, S.E. $=16, p<.05$ ). Wordmedially, the SPFs of tense affricates before /a/ also had a significant slope coefficient of Birthyear $\left(\mathrm{WM}\right.$-짜: $\beta_{\text {Birthyear }}=37$, S.E. $=12, p<.005$, when tested in another set of models by switching the reference level to /a/).

The females' model also had a significant coefficient of Birthyear in explaining the SPFs of the word-initial tense fricatives before /i/ 
(WI-씨: $\beta_{\text {Birthyear }}=33$, S.E. $=15, p<.05$, when tested in another set of models by switching the reference level to fricatives), indicating that young female adults' fricatives before /i/ have anterior frication POAs compared to older speakers (although tense fricatives before /i/ were still not as fronted as those before /a/ because the SPFs of the fricatives were significantly different between /a/ and /i/ (WI-씨: $\beta_{\text {Vowel }}=1,391$, S.E. $\left.=541, p<.05\right)$ ).

Reflecting the effect of age in the affricates' SPF variations, the regression models (year 2008 set as 0) showed that young female adults' affricates had SPFs almost as high as those of the fricatives + /a/ or had SPFs significantly higher than fricatives $+/ \mathrm{i} /$. The wordinitial model estimated that the SPF differences between tense affricates $+/ \mathrm{a} /$ and fricatives $+/ \mathrm{a} /$ were not significantly different (WI 짜-싸: $\beta_{\text {fric-aff }}=483$, S.E. $=747, p=.51$ ). In addition, word-medially, the SPFs of the affricates $+/ \mathrm{i} /$ were significantly higher than those of the fricatives $+/ \mathrm{i} /$ (see Table 2: WM 지-시: $\beta_{\text {fric-aff }}=-2,474$, S.E. $=408$, $p<.0001$; WM 찌-씨: $\beta_{\text {fric-aff }}=-626, \mathrm{~S} . \mathrm{E}=355, p<.1$ ). To summarize, the regression models showed that the young female speakers' affricate POAs were differentiated from those of the male speakers and older females by their fronted characteristics. The young female adults' affricates did not necessarily have constriction locations as back as those of the fricatives $+/ \mathrm{i} /$ (palato-alveolar constriction) and were not necessarily distinctively lower than those of fricatives $+/ \mathrm{a} /$ (alveolar constriction).

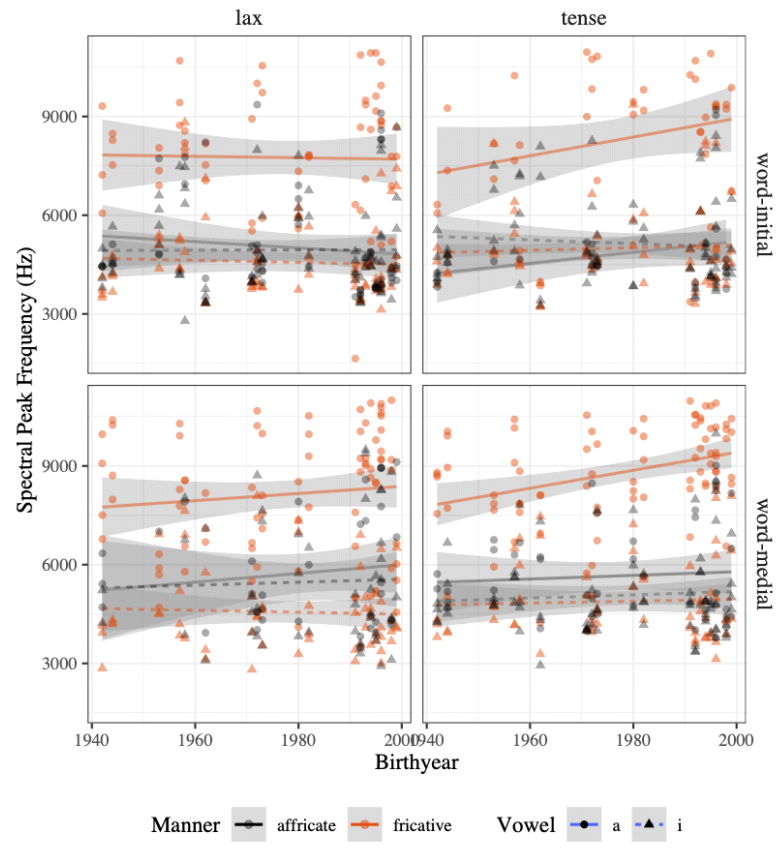

(a) Male speakers' sibilant productions

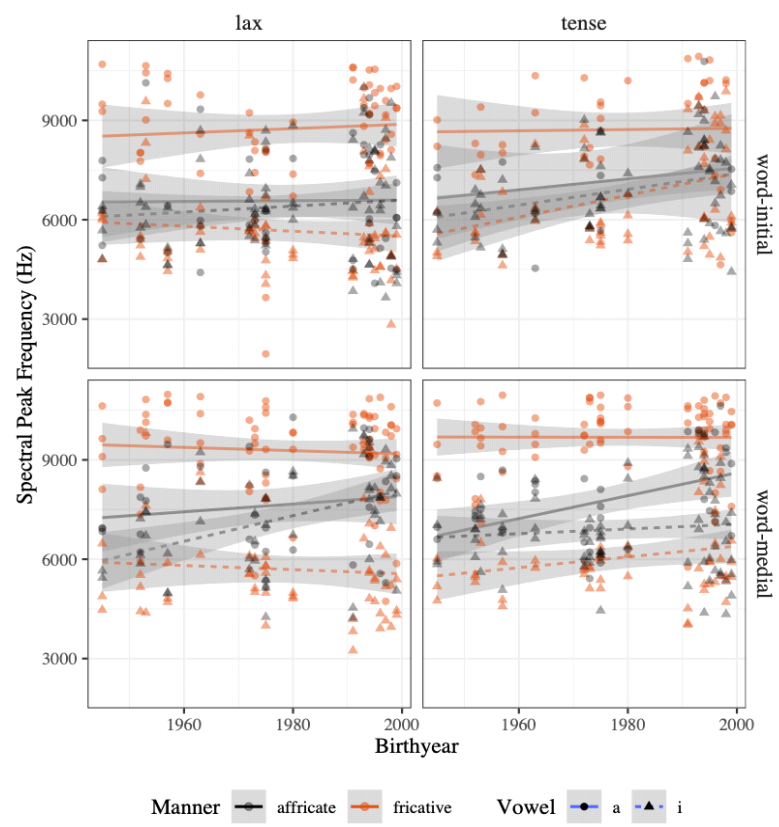

(b) Female speakers' sibilant productions

Figure 3. Scatterplots of sibilant SPFs as a function of speakers' birthyear: (a) male speakers' tokens and (b) females' tokens separated by phonation type (lax and tense), prosodic locations (word-initial and word-medial). Trend lines are overlaid based on linear regression coefficients of each consonant type

Table 1. Summaries of the mixed-effects regression models presented in Figure 3a: Models for male speakers' sibilant tokens. Models were made using a treatment coding scheme with affricate (vs. fricative) and /i/ (vs. /a/) as reference levels

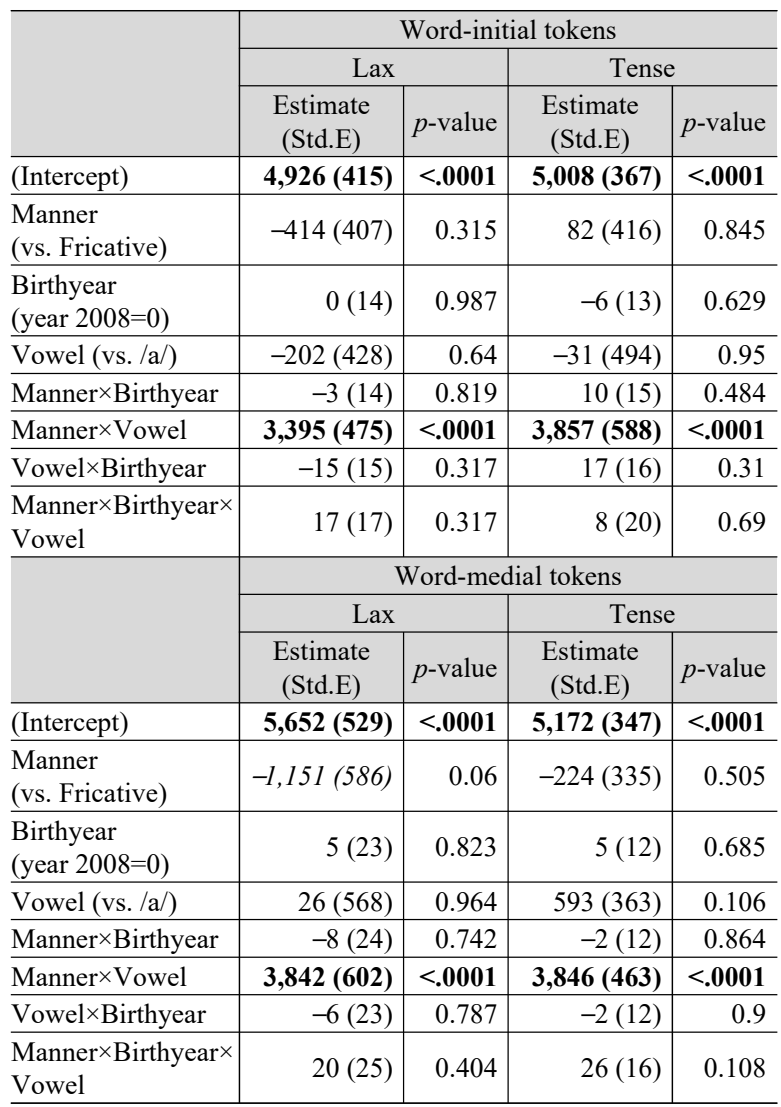


Table 2. Summaries of the mixed-effects regression models presented in Figure 3b: Models for female speakers' sibilant tokens. Models were made using a treatment coding scheme with affricate (vs. fricative) and /i/ (vs. /a/) as reference levels

\begin{tabular}{|c|c|c|c|c|}
\hline & \multicolumn{4}{|c|}{ Word-initial tokens } \\
\hline & \multicolumn{2}{|c|}{ Lax } & \multicolumn{2}{|c|}{ Tense } \\
\hline & $\begin{array}{l}\text { Estimate } \\
\text { (Std.E) }\end{array}$ & $p$-value & $\begin{array}{c}\text { Estimate } \\
\text { (Std.E) }\end{array}$ & $p$-value \\
\hline (Intercept) & $6,617(361)$ & $<.0001$ & 7,397 (279) & $<.0001$ \\
\hline $\begin{array}{l}\text { Manner } \\
\text { (vs. Fricative) }\end{array}$ & $-1,157(421)$ & 0.009 & $-28(381)$ & 0.942 \\
\hline $\begin{array}{l}\begin{array}{l}\text { Birthyear } \\
(\text { year 2008=0) }\end{array} \\
\end{array}$ & $9(14)$ & 0.531 & $24(10)$ & 0.032 \\
\hline Vowel (vs. /a/) & $10(454)$ & 0.983 & $880(800)$ & 0.277 \\
\hline Manner $\times$ Birthyear & $-18(16)$ & 0.26 & $9(14)$ & 0.55 \\
\hline Manner $\times$ Vowel & $3,407(504)$ & $<.0001$ & $512(774)$ & 0.509 \\
\hline Vowel $\times$ Birthyear & $-9(17)$ & 0.598 & $16(26)$ & 0.551 \\
\hline \multirow[t]{4}{*}{$\begin{array}{l}\text { Manner } \times \text { Birthyear } \\
\times \text { Vowel }\end{array}$} & $25(19)$ & 0.187 & $-47(25)$ & 0.064 \\
\hline & \multicolumn{4}{|c|}{ Word-medial tokens } \\
\hline & \multicolumn{2}{|c|}{ Lax } & \multicolumn{2}{|l|}{ Tense } \\
\hline & $\begin{array}{l}\text { Estimate } \\
\text { (Std.E) }\end{array}$ & $p$-value & $\begin{array}{c}\text { Estimate } \\
\text { (Std.E) }\end{array}$ & $p$-value \\
\hline (Intercept) & $8,042(444)$ & $<.0001$ & $7,048(302)$ & $<.0001$ \\
\hline $\begin{array}{l}\text { Manner } \\
\text { (vs. Fricative) }\end{array}$ & $-2,474(408)$ & $<.0001$ & $-626(355)$ & 0.086 \\
\hline $\begin{array}{l}\text { Birthyear } \\
(\text { year 2008=0) }\end{array}$ & 39 (16) & 0.03 & $7(11)$ & 0.537 \\
\hline Vowel (vs. /a/) & $-151(471)$ & 0.749 & $1,634(400)$ & $<.0001$ \\
\hline Manner $\times$ Birthyear & $-45(15)$ & 0.005 & $10(13)$ & 0.453 \\
\hline Manner $\times$ Vowel & $3,768(532)$ & $<.0001$ & $1,622(475)$ & 0.001 \\
\hline Vowel $\times$ Birthyear & $-29(17)$ & 0.088 & $30(14)$ & $\mathbf{0 . 0 3 9}$ \\
\hline $\begin{array}{l}\text { Manner } \times \text { Birthyear } \\
\times \text { Vowel }\end{array}$ & $31(19)$ & 0.115 & $-47(17)$ & 0.006 \\
\hline
\end{tabular}

\section{Discussion \& Conclusion}

The current study investigated the acoustic characteristics of the sibilant frication POA by comparing SPFs of young adults (university students in their 20s) and older adults (over 40s) speaking Seoul Korean. We were interested in examining the SPF patterns across speakers' ages to describe how the recent observations of gendered fronted sibilants were distributed across age groups in Seoul Korean. Our results revealed that there were age-differentiated patterns of sibilant SPFs, although not all phonetic contexts were subject to the age-related changes, and the female group had more contexts of age-differentiated patterns than the males. The finding that the age-related changes were not across the board but confined to specific phonetic contexts and gender groups convinces us that the systematic variations observed in sibilants are not mere reflections of physiological characteristics due to aging.

There were three major patterns of age-related sibilant variants: (1) tense affricates, (2) word-initial tense fricatives before /i/ and (3) word-medial tense fricatives before /a/. Across the cases, younger speakers' SPFs were consistently higher than those of older speakers, suggesting that those sibilants constitute fronted variants, and they represent new forms in the speech community. Furthermore, each of the three patterns was associated with one gender group but not with the other, either confirming previously reported gendered patterns of sibilant variants or reporting a novel pattern of gendered sibilant realizations.

Tense affricates by female young adults: Young females' tense affricates in the current study were fronted. The female speakers' word-initial tense affricates (/t6*/ 자) were almost as front as the alveolar fricatives before $/ \mathrm{a} /$ and the word-medial affricates were anterior to the (post-alveolar) fricatives before $/ \mathrm{i} /$. While the findings are in line with Kong et al. (2014), the current study has provided more refined descriptions of fronted affricates by extending the context to the word-initial position, and narrowly defining the fronted and new variants as those of young adult females'.

Word-initial tense fricatives before / $\mathbf{i}$ / by young females: Another age-differentiated pattern that emerged with respect to the female gender occurred with the young females' fronted fricatives in $/ \mathrm{s} * \mathrm{i} /$, where the word-initial tense fricatives before $/ \mathrm{i} /(/ \mathrm{s} * \mathrm{i} /$ 씨) exhibited increasing SPFs as a function of birthyear. This pattern is a novel finding of the present study as it has not been reported before. Even though those females' fricatives in $/ \mathrm{s}^{*} \mathrm{i} /$ were not as front as those in $/ \mathrm{s} * \mathrm{a} /$, the SPF differences between the $/ \mathrm{s} * \mathrm{i} /$ and $/ \mathrm{s} * \mathrm{a} /$ syllables were smaller in the young adult females than in the older females. This suggests that young adult females' fricatives before $/ \mathrm{i} /$ are realized not as a post-alveolar variant [6] but as a variant closer to the alveolar fricative [s]. In other words, allophonic differences of fricatives between $/ \mathrm{s} * \mathrm{a} /$ and $/ \mathrm{s} * \mathrm{i} /$ are lessened in females' productions. Although the pattern was observed in a limited context of wordinitial tense fricatives, it inspires an important future research question as to whether and how the fronted $/ \mathrm{s} * \mathrm{i} /$ influences speakers' phonological knowledge of fricative allophones.

Word-medial tense fricatives before /a/: There was one phonetic context of fricative realizations where male speakers showed age-related differences in SPF values: word-medial fricatives in $/ \mathrm{s} * \mathrm{a} /$. The acoustic evidence of higher SPFs suggests that the wordmedial $/ \mathrm{s}^{*} \mathrm{a} /$ produced by young adult males had constriction locations fronter than those of the older males. Given that the current study employed a subset of university students' fricatives reported in Kong \& Kang (2020), it was not surprising to observe this fronting pattern again in the younger males' word-medial fricatives. Instead, a unique contribution of the present study is that the fronted word-medial $/ \mathrm{s}^{*} \mathrm{a} /$ was characteristic of the young adult males but not of the older males, confirming that they are new phonetic forms. It is not clear based on the current analysis whether this fronted new variant of male fricatives in $/ \mathrm{s}^{*} \mathrm{a} /$ is related to the females' fronted fricatives in $/ \mathrm{s}^{*} \mathrm{i} /$ discussed above. We can only guess that they are not related because their vocalic contexts result in opposite consequences of fronting; unlike the females' fronted fricatives in $/ \mathrm{s} * \mathrm{i} /$, the fronted variant of the males' fricatives in $/ \mathrm{s} * \mathrm{a} /$ eventually makes fricative POAs between $/ \mathrm{s}^{*} \mathrm{a} /$ and $/ \mathrm{s}^{* \mathrm{i}} /$ distant, maintaining allophonic differences in the fricatives. Although not examined in the current analysis, Kong \& Kang (2020) described young male speakers' fricatives as having not only fronted (inferred from higher SPFs) but also less sibilant-like productions (inferred from diffused energy distributions measured). This additional acoustic characteristic also leads us to suspect that the male speakers' fricative fronting is not related to those of the females.

Based on the summaries of the three patterns of new fronted sibilants associated with the speakers' age and gender, we conclude that not only the speakers' age but also their gender was responsible for sibilant variations in Seoul Korean. On top of this, the results ensure that those new variants did not result from individual speakers' physiological differences as they occurred inconsistently across various contexts. Unfortunately, the current acoustic characteristics alone do not help us understand what else each form 
of fronted sibilants results from, and why each fronted sibilant is employed by specific gender group of young adults. The present study is only meaningful in establishing the necessary background acoustic knowledge to move forward in discussing more essential issues such as the linguistic or socio-indexical values of each variant for members of the speech community. Regardless of how finegrained the instrumental analyses might be applied, an acoustic analysis alone cannot explain the functions of these new variants linked to a specific gender group. Further research in the form of a qualitative survey is called for to investigate how each genderassociated variant is evaluated in the speech community, consciously or subconsciously.

\section{References}

Bates, D., Mäechler, M., Bolker, B., \& Walker, S. (2015). lme4: Linear mixed-effects models using Eigen and S4. R package version 1.1-7. 2014.

Eckert, P. (1989). The whole woman: sex and gender differences in variation. Language Variation and Change, 1(3), 245-267.

Flipsen P., Shriberg, L., Weismer, G., Karlsson, H., \& McSweeny, J. (1999). Acoustic characteristics of $/ \mathrm{s} /$ in adolescents. Journal of Speech, Language, and Hearing Research, 42(3), 663-677.

Hahm, H. J. (2007). The effects of following vowel on Korean fricatives. Linguistic Research, 24(1), 57-82.

$\mathrm{Hu}, \mathrm{M}$. (1991). Feminine accent in the Beijing vernacular: a sociolinguistic investigation. Journal of the Chinese Language Teachers Association, 26(1), 49-54.

Hume, E. (1990). Front vowels, palatal consonants and the rule of umlaut in Korean. North East Linguistics Society, 20(1), 230-243

Jongman, A., Wayland, R., \& Wong, S. (2000). Acoustic characteristics of English fricatives. The Journal of the Acoustical Society of America, 108(3), 1252-1263.

Kim, C. W., \& Ahn, S. (1988). "Palatalization in Korean revisited," in Sojourns in Language II; Collected papers by Chin-W. Kim (Tower Press, Seoul, SKorea), pp. 621-628.

Kong, E. J., \& Kang, J. (2020). Gendered spectral patterns of sibilant fricatives in Seoul Korean. Studies in Phonetics, Phonology and Morphology, 26(1), 1-19.

Kong, E. J., Kang, S., \& Seo, M. (2014). Gender difference in the affricate productions of young Seoul Korean speakers. The Journal of the Acoustical Society of America, 136(4), EL329-EL335.

Kuznetsova, A., Brockhoff, P. B., \& Christensen, R. H. B. (2017). lmerTest package: tests in linear mixed effects models. Journal of Statistical Software, 82(13), 1-26.

Labov, W. (1963). The social motivation of a sound change. Word, 19(3), 273-309.

Labov, W. (1990). The intersection of sex and social class in the course of linguistic change. Language Variation and Change, 2(2), 205-254.

Lee, H. Y. (1996). Kwuke um-seng-hak [Korean phonetics]. Seoul, Korea: Taehaksa.

Ohala, J. (1993). The phonetics of sound change. London, UK: Routledge.

Paul, B., \& David, W. (2021). Praat: doing phonetics by computer (version 6.1.39) [Computer program]. Retrieved from http://www. praat.org/

Psychology Software Tools [E-Prime 2.0]. (2016). Retrieved from https://support.pstnet.com/
R Core Team (2020). R: A language and environment for statistical computing. [Computer software]. Vienna, Austria: R Foundation for statistical computing. Retrieved from https:/www.R-project. org/

Sankoff, G. (2006). Age: apparent time and real time. Encyclopedia of language and linguistics, 110-116.

Shin, J. (2012). Sounds of the Korean Language. Seoul, Korea: Jisikgwa Gyeoyang.

Stuart-Smith, J. (2007). Empirical evidence for gendered speech production: /s/ in Glaswegian. In J. Cole \& J. I. Hualde (eds.), Laboratory phonology 9 (pp. 65-86). New York, NY: Mouton de Gruyter.

- Eun Jong Kong, corresponding author Professor, Dept. of English Korea Aerospace University 76 Hanggongdaehang-ro, Deogyang-gu, Goyang, 10540 Korea Tel: +82-2-300-0338

Email: ekong@kau.ac.kr

Fields of interest: Speech production \& perception, Language acquisition, Laboratory phonology

\section{- Jieun Kang}

Graduate student, Dept. of English Language and Literature Korea University 145 Anam-ro, Seongbuk-gu, Seoul, 02841 Korea Email: nppek@korea.ac.kr

Fields of interest: Speech production \& perception, Language acquisition, Laboratory phonology 


\section{Appendix 1. A full list of target words}

\begin{tabular}{|c|c|c|c|}
\hline \multicolumn{4}{|c|}{ Word-initial context } \\
\hline$/ \mathrm{sa} /$ & /si/ & $/ \mathrm{s}^{*} \mathrm{a} /$ & $/ \mathrm{s} * \mathrm{i} /$ \\
\hline /say.L/'상어' a shark & /si.kje/'시계' a clock & /s*a.um/ '싸움' a fight & /s*it.ta/ '씻다' to wash \\
\hline /sa.kwa/ '사과’ an apple & /si.kim.t6 ${ }^{\mathrm{h}} \mathrm{i} /$ '시금치' spinach & /s*ay.tun.i//쌍둥이'twins & $/ \mathrm{s} * \mathrm{i} . \lim /$ '씨름’ $a$ wrestling \\
\hline \multirow[t]{2}{*}{ /sa.tca/'사자' a lion } & /sik.p*ay/‘식 빵’ bread & & /s*i.at/'씨앗’ seed \\
\hline & /sip.tca.ka/ '십자가’ a cross & & \\
\hline$/ \mathrm{tca} /$ & $/ \mathrm{t} 6 \mathrm{i} /$ & $/ \mathrm{t}_{6} * \mathrm{a} /$ & $/ \mathrm{t} 6 * \mathrm{i} /$ \\
\hline /tcay.mi/ '장미' a rose & /tci.u.ke/‘지우개’ an eraser & 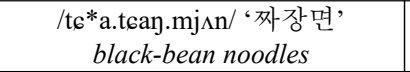 & /to*i.lix.ta/'찌르다' to poke \\
\hline /tcam.tca.li/ '잠자리' a dragonfly & /tci.kap/'지갑’ an wallet & /t6*a.tcixy/ '짜증' annoyance & /t6*i.ke/'찌개' stew \\
\hline /tca.ton.tc ${ }^{\mathrm{h}} \mathrm{a} /$ '자동차' a car & /tcin.tal.le/ '진달래' azalea & /t6*ak.su/ '짝수’ even numbers & /t6*im.t $\mathrm{t}^{\mathrm{h}}$ / / 찜통’ a steamer \\
\hline /tca.tu/'자두’ a plum & /tcin.t6u/'진주’ a pearl & $/ \mathrm{tc}^{*}$ am.p*oy/ '짬뽕' spicy noodles & /t6*in.p*ay/ '찐 빵' steamed buns \\
\hline \multicolumn{4}{|c|}{ Word-medial context } \\
\hline$/ \mathrm{sa} /$ & $/ \mathrm{si} /$ & $/ \mathrm{s} * \mathrm{a} /$ & $/ \mathrm{s} * \mathrm{i} /$ \\
\hline /hwa.sal/ '화살' an arrow & /t6ım.sim/“점심’ lunch & /pal.sa/ '발사’ launch & /kok.sik/ '곡식' grains \\
\hline /ii.sa/ '의사' a doctor & /kjo.sil/ '교실' a classroom & /het.sal/ '햇살' sunlight & /t6ıp.si/'접시'a dish \\
\hline /in.sam/ ‘인삼’ ginseng & /ka.si/'가시' a thorn & /jak.sa/ '약사' a pharmacist & /nal.s*i/ '날씨' weather \\
\hline /kan.ho.sa/ ‘간호사’ a nurse & & /se.s*ak/‘새싹’ sprouts & \\
\hline$/ \mathrm{t} 6 \mathrm{a} /$ & $/ \mathrm{t} 6 \mathrm{i} /$ & $/ \mathrm{tc}^{*} \mathrm{a} /$ & $/ \mathrm{t}_{6} * \mathrm{i} /$ \\
\hline /kwa.tca/ '과자' snacks & /tci.tcin/ '지진' an earthquake & /kik.tcay/ '극장' a theater & /k* $\Lambda$ p.tcil/ ‘껍ㅈㅣㅣㄹ' skins \\
\hline /hwa.tcay/ '화장' make-ups & /twe.tci/'돼지' a pig & /han.tca/ '한자' Chinese characters & /pal.t6*i/ '발찌' a leg bracelet \\
\hline \multirow[t]{2}{*}{ /mo.tca/ '모자' a cap } & /hju.tci/ ‘휴지' toilet papers & /nal.t6*a/ '날짜’ dates & /p*an.tcip/ ‘빵집’ a bakery \\
\hline & & & /phal.t6*i/ '팔찌' a bracelet \\
\hline
\end{tabular}

